\title{
ARTIGOS
}

\section{O PAPEL DA PETROBRAS NA ECONOMIA BRASILEIRA (2003/2018): ASCENSÃO E QUEDA}

\author{
Álisson Riceto ${ }^{1}$ \\ Universidade Federal de Goiás
}

Ronaldo da Silva ${ }^{2}$

Universidade Federal de Uberlândia

Enviado em 20 nov. 2019 | Aceito em 5 nov. 2020

Resumo: Entre 2003 e 2018, o Brasil viveu quadros socioeconômicos opostos. Até 2013/14, a economia seguiu crescendo com melhora em seus indicadores impulsionados pelos investimentos no setor de petróleo e gás natural gerido pela Petrobras. O maior volume de recurso destinado ao desenvolvimento tecnológico viabilizou a nova fronteira exploratória do pré-sal. Nesse setor, a atuação geoeconômica do governo brasileiro tornou a Petrobras protagonista com um novo Marco Regulatório de exploração, reforçando a Política de Conteúdo Local (PCL), além de estimular investimentos em grande número de setores complementares, possibilitando à estatal ganhar ainda mais destaque no mercado mundial. No entanto, a partir de 2014, a somatória de fatores domésticos e internacionais promoveu uma reviravolta nesse período virtuoso. Profundamente afetada pela Operação Lava Jato e pela acentuada desvalorização do petróleo no mercado internacional entre 2014 e 2016, a Petrobras teve sua direção radicalmente alterada, em especial nos governos de Michel Temer e Jair Bolsonaro. Desde então, às voltas com uma nova filosofia de gestão, vem reduzindo seus investimentos e tendo campos de exploração, segmentos e subsidiárias privatizados. Neste cenário, a estagnação do crescimento e, mesmo a redução do PIB, a elevação do desemprego, a desvalorização da moeda, a ampliação da concentração de riqueza e a instabilidade política são latentes no país. Dessa forma, com base na análise de relatórios e artigos recentes, o objetivo deste trabalho é esclarecer estes dois momentos e mostrar como a Petrobras e o setor de petróleo e gás natural estão no centro dos acontecimentos políticos e socioeconômicos recentes da sociedade brasileira.

Palavras-chave: Petrobras; Geoeconomia; Crise.

\section{PETROBRAS' ROLE IN THE BRAZILIAN ECONOMY (2003/2018): RISE AND FALL}

Abstract: Between 2003 and 2018, Brazil experienced opposing socioeconomic conditions. Until 2013/14, the economy continued to grow, socioeconomic indicators improved, and much of this was driven by investments in the oil and natural gas sector headed by Petrobras. Within these, investments in technological development to make the new exploratory frontier for the pre-salt feasible stood out. In this sector, the geoeconomic performance of the Brazilian government, making Petrobras the protagonist with a new regulatory framework for exploration and reinforcing the Local Content Policy (PCL), in addition to stimulating investments in a large number of complementary sectors, made the state company gain even more prominence on the world market. However, as of 2014, the sum of domestic and international factors brought about a turnaround in this virtuous period. Deeply affected by Operation Lava Jato, by the sharp devaluation of oil in the international market between 2014 and 2016, Petrobras had its direction radically changed, especially in the governments of Michel Temer and Jair Bolsonaro. Since then, dealing with a new management philosophy, it has been reducing its investments and having privatized exploration fields, segments and subsidiaries. In this scenario, stagnant growth and even a reduction in GDP, rising unemployment, currency devaluation, an increase in the concentration of wealth and political instability are latent in the country. Thus, based on the analysis of recent reports and articles, the objective of this paper is to clarify these two moments and show how Petrobras and the oil and natural gas sector are at the center of the recent political and socioeconomic events in Brazilian society.

Keywords: Petrobras; Geoeconomics; Crisis.

\section{EL PAPEL DE PETROBRAS EN LA ECONOMÍA BRASILEÑA (2003/2018): SUBIDA Y BAJADA}

Resumen: Entre 2003 y 2018, Brasil experimentó condiciones socioeconómicas opuestas. Hasta 2013/14, la economía siguió creciendo, los indicadores socioeconómicos mejoraron y gran parte de esto fue impulsado por inversiones en el sector de petróleo y gas natural encabezado por Petrobras. Entre ellas, ganan relieve las inversiones en desarrollo tecnológico para viabilizar la nueva frontera exploratoria del presal. En este sector, el desempeño geoeconómico del gobierno brasileño (haciendo de Petrobras la protagonista con un nuevo marco

1. Mestre em Geografia pela Universidade Federal de Goiás - UFG/RC. Professor na rede privada. E-mail: geoalisson@gmail.com. ORCID: https://orcid.org/0000-0002-2949-2171

2. Doutor em Geografia pela Universidade Federal de Uberlândia - UFU, Professor Associado 1 - UFCAT - Instituto de Geografia. E-mail: ronaldogeografia@yahoo.com.br. ORCID: https://orcid.org/0000-0001-6280-9313 
regulatorio para la exploración y reforzando la Política de Contenido Local - PCL), además de estimular inversiones en un gran número de sectores complementarios, hizo que la empresa estatal ganara aún más protagonismo en el mercado mundial. Sin embargo, a partir de 2014, la suma de elementos nacionales e internacionales impulsó un vuelco en este período virtuoso. Profundamente afectada por la "Operación Lava Jato", por la fuerte devaluación del petróleo en el mercado internacional entre 2014 y 2016, Petrobras cambió radicalmente su rumbo, especialmente en los gobiernos de Michel Temer y Jair Bolsonaro. Desde entonces, con una nueva filosofía de gestión, ha reducido sus inversiones y privatizando campos, segmentos y sucursales de exploración. En este contexto, el estancamiento del crecimiento e incluso una reducción del PIB, el aumento del desempleo, la devaluación de la moneda, un aumento en la concentración de la riqueza y la inestabilidad política están latentes en el país. Así, a partir del análisis de informes y artículos recientes, el objetivo de este trabajo es esclarecer estos dos momentos y mostrar como Petrobras y el sector de petróleo y gas natural están en el centro de los recientes acontecimientos políticos y socioeconómicos de la sociedad brasileña.

Palabras clave: Petrobras; Geoeconomía; Crisis.

Introdução

Ao longo deste século, o setor de petróleo e gás natural, e por consequência a Petrobras, principal empresa do setor atuante no Brasil, assumiram grande protagonismo na economia e política nacionais. A descoberta das reservas do pré-sal, em 2006, somado a um novo marco regulatório, no ano de 2010, dinamizaram a cadeia produtiva associada ao setor. As indústrias metalomecânica, naval, de engenharia, dentre outras, foram impulsionadas pela Política de Conteúdo Local (PCL). A Petrobras passou a representar parte relevante dos investimentos diretos e do PIB nacional.

Entretanto, desde 2013/2014, com o agravamento do quadro de instabilidade política no país e, principalmente, após o golpe jurídico-parlamentar contra a ex-presidente Dilma Rousseff, o cenário se inverteu. A Petrobras perdeu grande parte de seu protagonismo e valor de mercado, o marco regulatório de exploração do pré-sal foi flexibilizado e ativos estratégicos da empresa foram liquidados. Derivado desse cenário, o país ingressou em uma das mais profundas crises política e socioeconômica de sua história.

Este trabalho, que é parte de uma dissertação de mestrado produzida pelo primeiro autor e orientada pelo segundo, foi inspirado por esse cenário, e é constituído por dois objetivos. O primeiro será demonstrar o papel crucial da Petrobras e do setor de petróleo e gás natural na economia brasileira, entre 2003 e 2018 e entender como as ações geoeconômicas do Estado brasileiro, tomando a estatal e o referido setor, estimularam o desenvolvimento estratégico de novas tecnologias e segmentos de mercado e apresentar os efeitos de tais articulações. O segundo será analisar como fatores de ordem doméstica e internacional contribuíram para o endividamento e posterior desmonte da estatal e setores complementares, gerando uma espiral de consequências socioeconômicas negativas.

O artigo está organizado em três partes, sendo a última destinada às Considerações Finais. Na primeira, pretende-se mostrar como, a partir da descoberta das jazidas do pré-sal e sob um novo marco regulatório, a Petrobras assumiu um papel central no avanço tecnológico e na economia nacional. Como a estatal, firmando parcerias com centros de pesquisas e universidades, realizando volumosos investimentos e apoiada na PCL, fez crescer o PIB, gerou empregos, resgatou setores então sucateados e alargou nossa fronteira tecnológica.

Na segunda, deve-se discutir o processo de fragilização da empresa petrolífera nas escalas nacional e internacional e a relação disso com o cenário socioeconômico profundamente negativo 
estabelecido no país. Para tanto, serão apresentados os fatores responsáveis por tal cenário, dentre os quais estão: os efeitos econômicos da Operação Lava-Jato, as desvalorizações do petróleo e do Real, a ampliação dos investimentos e da alavancagem da empresa, bem como a flexibilização do Marco Regulatório do Pré-sal.

Deve-se demonstrar como a condução questionável da Operação Lava Jato, baseada no discurso de combate à corrupção, debilitou a empresa e setores complementares. Dentro disso, como o discurso de um endividamento insustentável serviu para endossar a flexibilização do Marco Regulatório do Pré-Sal e para a venda de ativos da empresa, comprometendo o sistema de produção "do poço ao posto" que ainda está em curso.

Trata-se de uma abordagem teórica sustentada por referências bibliográficas, coleta, tabulação e análise de dados obtidos a partir de relatórios da Petrobras e de outras empresas e organismos especializados, tais como os relatórios da British Petroleum (BP), da Pré-Sal S.A., e do Instituto de Pesquisa Econômica Aplicada (IPEA).

Também foram considerados artigos, entrevistas e dados publicados por entidades e profissionais diretamente ligados ao tema, tais como o Instituto de Estudos Estratégicos de Petróleo, Gás Natural e Biocombustíveis Zé Eduardo Dutra (INEEP) e a Federação Única dos Petroleiros (FUP). Foram utilizadas ainda as Leis Federais $n^{0} 12.351 / 10$ e $n^{0} 12.276 / 10$, as quais sustentam o Marco Regulatório do Pré-sal e entrevistas de Guilherme Estrella, ex-diretor de Exploração e Produção (E\&P) da Petrobras entre 2003 e 2012.

\section{Articulação geoeconômica da Petrobras na economia brasileira}

Antes das descobertas das reservas da camada pré-sal, a Petrobras intensificou sua atuação no mercado internacional, em especial na América do Sul e na África. Inaugurando e/ou ampliado sua presença em 23 países, em diversas etapas do circuito espacial produtivo do petróleo e do gás natural, a empresa atingiu todos os continentes (RICETO, 2019).

Entretanto, a descoberta do pré-sal redirecionou os esforços da empresa para os desafios técnicos e econômicos de viabilizar a exploração nessa nova fronteira. Com a implantação do Marco Regulatório do Pré-sal (Lei Federal 12.351/10), a Petrobras assumiu a posição estratégica de única operadora dos consórcios, os quais deveriam representar ao menos $30 \%$ do investimento. Ainda, por meio da Lei Federal n 12.276 de 30 de junho de 2010, áreas de grande potencial produtivo foram cedidas estrategicamente à empresa ${ }^{3}$.

Este novo arranjo jurídico, apoiado nas referidas leis, foi pensado diante das grandes perspectivas de volume e qualidade das reservas de petróleo e gás natural do pré-sal, há pouco descobertas. O governo, à época, tratava tais reservas como uma mola propulsora do desenvolvimento socioeconômico e tecnológico nacional. Para tanto, na composição original, o Marco Regulatório estabeleceu: a) o modelo de concessão por partilha, no qual o óleo lucro, ou seja, o excedente, após deduzidos todos os custos de produção, deve ser repartido entre o contratado (empresa e/ou consórcio) e a União; b) a Petrobras como única operadora dos consórcios, com participação percentual mínima; c) a criação do Fundo Social do Pré-sal (FSPS) que, fomentado por parcela dos bônus de assinatura, dos royalties que couberem à União, da comercialização do petróleo e do gás natural pertencentes ao Estado, e dos resultados das aplicações financeiras feitas pelo próprio fundo, destina-se ao financiamento de programas de combate à pobreza e desenvolvimento

3. Modelo este denominado Cessão Onerosa, a União, sem licitação, concedeu à Petrobras blocos e campos integrantes do pré-sal ainda não concedidos, limitados a 5.000 .000 de barris, mediante pagamento de royalties e participações especiais pela empresa. 
socioeconômico, com destaque para os investimentos em educação, ciência e tecnologia, cultura, saúde pública e meio ambiente.

Neste Marco Regulatório também se reforçou a aplicação da Política de Conteúdo Local (PCL) definida como a "proporção entre o valor dos bens produzidos e dos serviços prestados no País para execução do contrato e o valor total dos bens utilizados e dos serviços prestados para essa finalidade" (Art. 2, inciso VIII). Os percentuais de conteúdo local (CL) são estipulados nas licitações.

No leilão do campo de Libra, realizado outubro de 2013, o primeiro sob esse novo marco, foram estabelecidos 37\% de CL na fase de exploração, 55\% na fase de desenvolvimento até 2021 e 59\% depois desse ano ${ }^{4}$. Intensificado durante os governos de Luiz Inácio Lula da Silva $(2003 / 2010)^{5}$, tal mecanismo estimulou o desenvolvimento e a retomada de investimentos complementares à exploração do petróleo e do gás natural. Serviu ainda para modernizar segmentos importantes do circuito espacial produtivo no país e, com o desenvolvimento da tecnologia nacional, colaborou para o protagonismo da Petrobras no cenário internacional da exploração de hidrocarbonetos offshore (AZEVEDO, 2018).

A PCL é uma política de Estado que, apesar de complexa e dependente de uma série de complementações de ordem financeira, fiscal e educacional, se bem articulada, pode estimular o desenvolvimento e a diversificação da capacidade produtiva do país, assim como o know how das empresas nacionais. Na verdade, a PCL estimula a

\begin{abstract}
geração de mais empregos e renda, diversificação da economia local, crescimento sustentável da economia, ambiente seguro para atração de investimentos, desenvolvimento da capacidade produtiva local e aumento da arrecadação de impostos. Como efeitos positivos dessa política, foram destacados os resultados obtidos com o fortalecimento da indústria naval brasileira. Os estaleiros em operação, por exemplo, passaram de 2 em 2003 para 14 em 2014 (sendo 5 em construção). Passamos de 7.465 empregos diretos em 2003, para 82.472 em 2014. A carteira de encomendas passou de 2 construções de módulos e integrações de FPSOs em 2003, para 8 construções de cascos, 4 conversões de cascos, 16 construções de módulos e integrações de FPSOs, 28 sondas de perfuração e 40 navios petroleiros em 2014. (FUP, 2016, p. 4).
\end{abstract}

Vale destacar, ainda, que esse novo marco também manteve os percentuais de investimentos em Pesquisa, Desenvolvimento e Inovação (PD\&l), sendo 1\% da receita bruta anual para as áreas exploradas pelo modelo de partilha e $0,5 \%$ para as concedidas por meio da cessão onerosa. Nesse sentido, ao longo do século XXI, a Petrobras se sobressai enormemente na busca por uma articulação estratégica com universidades, centros técnicos e de pesquisa para incrementar a PD\&I no país.

Desde 2006, foram criados núcleos de pesquisa com várias instituições para melhor direcionar tais investimentos. Sob coordenação do Centro de Pesquisa e Desenvolvimento Leopoldo Américo Miguez de Mello (CENPES) ${ }^{6}$, formou-se uma ampla rede de pesquisa e desenvolvimento em território nacional envolvendo mais de 100 universidades onde foi possível implantar laboratórios, adquirir equipamentos e formar pesquisadores e técnicos em todas as áreas do setor de exploração e produção de petróleo e gás natural, graças a uma política eficiente de incentivos. Com este quadro, a Petrobras se transformou na empresa que mais investia em Ciência e Tecnologia (C\&T) no país.

4. Segundo reportagem da BBC Brasil, de 21 de outubro de 2013. Disponível em: <http://www.bbc.com/portuguese/noticias/2013/10/131018_modelo_libra_ru>. Acesso em: 03 set. 2017.

5. De acordo com dados dos gráficos 1 e 2, páginas 29 e 30, do relatório Custos e Benefícios da Política de Conteúdo Local, de outubro de 2016. Disponível em: <https://www.ibp.org.br/personalizado/uploads/2016/09/2016_TD_Custos-eBenef\%C3\%ADcios-da-Pol\%C3\%ADtica-Conte\%C3\%BAdo-Local.pdf>. Acessado em: out. 2018.

6. Criado em 1973 e hoje considerado um dos principais centros de pesquisa no setor de energia do mundo, o Centro de Pesquisa e Desenvolvimento Leopoldo Américo Miguez de Mello (Cenpes), localizado na Ilha do Fundão, no Rio de Janeiro, tem a missão de fornecer e antecipar soluções tecnológicas em produtos e processos para o Sistema Petrobras. 
Assim, o período compreendido entre 1998 e o final de 2017, dos R\$12,9 bilhões investidos pelas empresas do setor em PD\&l, a Petrobras foi responsável por R\$ 12 bilhões. Porém, o protagonismo da estatal vem diminuindo desde 2014/2015, visto que os investimentos foram de R\$ 713 milhões em 2017, pouco mais de 57\% do total investido em 2014 (AZEVEDO, 2018).

Loural (2016) destaca que os investimentos da Petrobras entre 1999 e 2013 contribuíram expressivamente para o crescimento do PIB brasileiro e, de 2002 a 2013, os investimentos diretos da empresa foram superiores à soma dos gastos de outras 72 grandes empresas de capital aberto no Brasil. Ressalta ainda que a taxa de investimentos da economia brasileira (volume de investimentos em relação ao PIB), entre 1999/2013, variou na faixa de 15\% e 20\%, relação de dependência direta com os investimentos da Petrobras e da Vale S.A., sendo a petroleira a mais destacada.

A ação geoeconômica de um Estado consiste na adoção de políticas estratégicas com o intuito de proteger sua economia nacional ou nichos específicos, seja na produção ou na comercialização em segmentos sensíveis do mercado global cujo protagonismo oferece ao titular grande influência internacional e contribui para o fortalecimento de seu potencial socioeconômico (Lorot, 1999, p. 15, apud EGLER, 2012, p. 85), aspectos destacados na posição do governo brasileiro à época. Articulavase para que a exploração dessas novas reservas, mesclando capitais nacionais e estrangeiros, estivesse sob a coordenação da empresa estatal, e ocorresse em ritmo e padrões adequados aos interesses do mercado nacional e internacional, mas também do Estado brasileiro.

Gradualmente, tais medidas surtiram efeito. Dados divulgados por representantes da Petrobras em 2014, na $21^{\circ}$ Conferência Mundial do Petróleo (WPC) ${ }^{7}$, realizada em Moscou, revelaram que a participação do circuito espacial produtivo do petróleo e do gás natural no PIB brasileiro aumentou de 3\% em 2000 para 13\% naquele ano. No mesmo evento, também foi destacada a importância da PCL, do Programa de Mobilização da Indústria Nacional de Petróleo e Gás Natural (Prominp), da parceria com o Serviço Brasileiro de Apoio às Micro e Pequenas Empresas (SEBRAE), que aumentou em mais de $30 \%$ o número de pequenas e médias empresas na cadeia de fornecedores da Petrobras, e do alinhamento das empresas operadoras dos consórcios de exploração a essas políticas.

A somatória dos investimentos da Petrobras na exploração offshore com a PCL impulsionou o crescimento do setor ${ }^{8}$. Entre 2000 e 2010, a indústria naval viu sua receita total avançar a uma média de 19,5\% ao ano (IPEA, 2014, p. 162). José Alcides Santoro, um dos diretores da Petrobras à época, reforçando o exposto até aqui, entende que tal alinhamento abriu uma fase áurea para a indústria naval brasileira, pois, "em 2003, apenas dois estaleiros estavam em funcionamento e o número de empregos no setor totalizava 7.465. Este ano (2014), já são dez estaleiros de médio e grande porte em funcionamento, 80 mil empregos diretos e, aproximadamente, 320 mil indiretos". E previa que "em 2017, o número de vagas diretas nos estaleiros deverá chegar a 101 mil” . Entretanto, esta previsão não se confirmou. Dados do Sindicato Nacional da Indústria da Construção e Reparação Naval e Offshore (Sinaval) mostram que, em abril de 2018, os estaleiros nacionais empregavam apenas 29.539 trabalhadores contra 82.472 em dezembro de 2014. Vale ressaltar que os estaleiros, apesar de concentrados no estado do Rio de Janeiro, estavam espalhados pelo litoral brasileiro, com unidades em Santa Catarina, no Rio Grande do Sul, na Bahia e em Pernambuco.

7. Disponível em: <https://www.agenciapetrobras.com.br/Materia/ExibirMateria?p_materia=976480\&p_editoria=11>. Acessado em: 18 jul. 2018.

8. Segundo o Sindicato Nacional da Indústria da Construção e Reparação Naval e Offshore (Sinaval), em abril de 2018, os estaleiros nacionais empregavam 29.539 trabalhadores, contra 82.472 em dezembro de 2014. Disponível em: <http://sinaval.org.br/2018/07/industria-naval-brasileira-vive-grave-crise-a-espera-de-encomendas-com-queda-de-64-nosempregos-desde-2014/>. Acessado em: 24 jul. 2020.

9. Disponível em: <https://www.agenciapetrobras.com.br/Materia/ExibirMateria?p_materia=976480\&p_editoria=11>. Acessado em: 18 jul. 2018. 
Nessa mesma direção, Oliveira e Coutinho (2017) apontam que, para cada US\$1.000,00 investidos pela Petrobras, são gerados cerca de US\$ 650,00 em investimentos em outros setores. Estudo da Secretaria de Política Econômica, órgão do Ministério da Fazenda (SPE-MF), publicado em 21 de outubro de 2015, indicava que a companhia foi responsável por 8,8\% do total dos investimentos no Brasil, o que representou 1,8\% do PIB. Nessa direção, "para cada R\$ 1 bilhão gastos em investimentos no país ocorre a geração de cerca de R\$ 860 milhões no PIB (valor adicionado) brasileiro e de 19.300 novos postos de trabalho" (PINTO; PEREIRA, 2017, p. 2).

Investigação realizada pelo Instituto de Estudos Estratégicos de Petróleo, Gás Natural e Biocombustíveis Zé Eduardo Dutra (INEEP) utilizando o método da Matriz de Absorção do Investimento (MAI) desenvolvido pelo Grupo de Indústria e Competitividade do IE/UFRJ considerou apenas os investimentos nos encadeamentos produtivos para mostrar que a cada R\$ 1 bilhão investido em E\&P são gerados R\$ 1,28 bilhão no PIB e 26.319 ocupações. Enquanto que, a cada R\$ 1 bilhão realizado no refino, há uma geração de R\$ 1,27 bilhão no PIB e de 32.348 ocupações (PINTO; DWECK, 2018).

Assim, torna-se inegável que, na primeira década e meia deste século, a

Petrobras se transformou numa peça-chave do desenvolvimento econômico do país, chegando a ser responsável por cerca de 13\% do PIB brasileiro e 8,4\% da formação bruta do seu capital fixo, com um investimento - entre 2003 e 2015 - de 1,6\% do PIB brasileiro. (Fiori, 2019, p. 31)

Com sua grande carteira de ativos e volumosos investimentos nos mais diversos países, avançado capital tecnológico, especialmente em exploração offshore em águas ultraprofundas, investimentos realizados na compra e na construção de grandes refinarias, como a de Pasadena, no Texas (EUA) ${ }^{10}$, o Complexo Petroquímico do Rio de Janeiro (COMPERJ), no município de Itaboraí, e de Abreu e Lima, em Ipojuca (PE), estimados em US\$ 50 bilhões, atrelados ao protagonismo concedido pelo Marco Regulatório do Pré-sal, a Petrobras assumiu o papel de player global no setor de energia fóssil, cenário previsto em 2006 pelo The New York Times que destaca investimentos da empresa em diversos países ${ }^{11}$.

Um player global é definido pela representatividade que um país ou uma empresa possui no direcionamento dos diferentes aspectos do Sistema Internacional (SI). No caso de empresas, em especial das que atuam em setores estratégicos como o de energia, sua estrutura e potencial produtivo, seu arcabouço tecnológico e seu conjunto de ativos pesam nessa classificação cujo status foi alcançado pela Petrobras entre 2000 e 2015.

No início de 2011, a PFC Energy classificou a Petrobras como a terceira maior empresa de energia do mundo superando Shell e Chevron, com valor de mercado estimado em US\$228,9 bilhões em dezembro de 2010. Em 1999, a Petrobras era a $27^{a}$ neste mesmo ranking ${ }^{12}$. Dentre as várias premiações recebidas, em 2015, pela terceira vez, a Petrobras recebeu o prêmio OTC Distinguished AchievementAward for Companies, Organizations, and Institutions em reconhecimento ao conjunto de tecnologias desenvolvidas para a produção da camada pré-sal. Tomado como o maior prêmio possível para uma empresa do setor, esse fato retratava a relevância assumida pelo desenvolvimento tecnológico da empresa e o seu protagonismo assumido no mundo. Com o golpe de 2016 contra a

10. Vendida para a Chevron em 2019.

11. Disponível em: <https://www.bbc.com/portuguese/reporterbbc/story/2006/07/060707_pressreview_crg.shtml>. Acesso em: 14 jul. 2018.

12. Disponível em: <https://economia.estadao.com.br/noticias/negocios,petrobras-e-a-3-maior-companhia-de-energia-domundo,52260e>. Acesso em: 24 jul. 2020. 
presidente Dilma Rousseff e a formação do governo de Michel Temer, que inverteu a lógica e os objetivos da política administrativa da estatal, o cenário de prosperidade logo mudaria.

\section{Oscilações de mercado, Operação Lava Jato e os prejuízos para a Petrobras}

Entre 2014 e 2016, a Petrobras passou a enfrentar as consequências negativas da Operação Lava Jato. Lançada em março de 2014, consiste em investigações conduzidas pelo Ministério Público Federal (MPF) sobre esquemas de superfaturamento de contratos, fraudes em licitações e propinas de empresas privadas a diretores de estatais e projetos públicos, envolvendo dezenas de partidos políticos, tendo como cerne empreendimentos da petroleira ${ }^{13}$.

A divulgação seletiva e minimamente espetaculosa de informações desta operação ${ }^{14}$ por procuradores e grandes veículos de mídia atingiu mundialmente a imagem da Petrobras. Segundo relatório da estatal divulgado em abril de 2015, com base nas investigações do MPF, a empresa havia perdido R\$ 6,2 bilhões com desvios e fraudes, entretanto, a Polícia Federal (PF) estimava na ocasião que o rombo pudesse chegar a $\mathrm{R} \$ 43$ bilhões $^{15}$

Com a divulgação dos casos de corrupção envolvendo seus diretores, as ações da estatal sofreram intensa desvalorização reduzindo significativamente seu valor de mercado ${ }^{16}$. As incertezas quanto à transparência, à viabilidade de seus investimentos e à lisura de seus projetos afastaram os investidores. Nos EUA, grandes fundos de investimentos desfizeram-se rapidamente de ações e títulos da petroleira. Entre julho e dezembro de 2014, a empresa perdeu 51\% do seu valor de mercado, sendo avaliada em R\$ 127 bilhões, aproximadamente US\$ 48 bilhões, na cotação do final daquele ano (GOULART, 2014).

No primeiro trimestre de 2016, o valor de mercado da Petrobras chegou a R\$ 73,7 bilhões, uma redução de $85 \%$ quando comparada aos números de maio de 2008, período do auge histórico da empresa quando sua avaliação ultrapassou R\$ 510 bilhões, estando 33\% frente aos mais de R\$ 214 bilhões em que era avaliada em dezembro de 2013. Em 17 de março de 2016, exatos dois anos após o início da Operação Lava Jato, as ações preferenciais eram comercializadas a R\$ 8,10. Dois anos antes, eram vendidas a R $\$ 11,84^{17}$. Morais (2017) destaca que, somados aos resultados econômicos ruins apresentados pela empresa em 2014, os desdobramentos da força-tarefa tiveram grande responsabilidade sobre o quadro de crise vivido pela petrolífera, que naquele ano apresentou prejuízo de US\$ 7,4 bilhões.

Nesse sentido, Nozaki (2018) aponta que, sob o discurso de combate à corrupção, iniciou-se um processo de desmonte de importantes setores da economia nacional. Dentre os mais afetados se destaca a indústria do petróleo e sua carteira de fornecedores, tais como a indústria naval, a construção civil, a metalomecânica e a engenharia pesada. São segmentos que, pelo seu potencial e caráter estratégico, tanto interessam a empresas transnacionais. Isso retirou da economia brasileira mais de R\$ 142 bilhões, apenas no primeiro ano da Operação.

13. Para maiores detalhes sobre tal operação ver: <http://arte.folha.uol.com.br/poder/operacao-lava-jato/>. Acesso em: 16 jul. 2018.

14. Que em 18 de junho de 2020 teve sua $71^{\text {a }}$ fase iniciada.

15. Disponível em: <https://brasil.elpais.com/brasil/2016/01/12/economia/1452625037_799572.html>. Acesso em: 22 jul. 2018.

16. O valor de mercado é a multiplicação do valor unitário das ações pelo número de ações existentes.

17. Dados das reportagens do portal UOL, dos dias 19/01/2016 e 21/03/2016. Disponíveis em: <https://economia.uol.com.br/noticias/redacao/2016/01/19/petrobras-perde-r-4366-bi-em-valor-de-mercado-desde-2008diz-consultoria.htm> e <https://economia.uol.com.br/noticias/redacao/2016/03/21/crise-da-petrobras-dura-2-anos-comqueda-de-acao-prisao-divida-e-processo.htm>. Acesso em: 17 jul. 2018. 
O autor ainda afirma que a retração dos investimentos da Petrobras chegou a 2\% do PIB, enquanto dos investimentos das construtoras e empreiteiras chegou a 2,8\% do PIB de 2015. Em 2016, os reflexos da Operação fez encolher em $5 \%$ os investimentos em formação bruta de capital fixo no Brasil e em mais de R\$ 100 bilhões o faturamento das empresas arroladas nela. Por último, a indústria naval, que em 2014 empregava mais de 84.000 pessoas, em setembro de 2018 contava com cerca de 25.000 trabalhadores $^{18}$. Reforçando essa tese, o estudo da SPE-MF, supracitado, aponta que, em 2015, os cortes na Petrobras e as consequências da Lava Jato resultaram na retração de, ao menos, $2 \%$ do PIB brasileiro.

Destarte, os prejuízos causados pelas revelações da Operação Lava Jato à economia brasileira, e em especial à imagem e ao valor de mercado da Petrobras, são inegáveis e muito significativos. Esses prejuízos tornaram-se ainda mais relevantes pela conjuntura. Entre 2006 e 2013, a Petrobras ampliou em $420 \%$ suas projeções de investimentos, demandando assim maior geração de caixa. Em situação oposta seria necessário recorrer a novos empréstimos, emissão de títulos de dívida e/ou ações no mercado, desinvestimentos ou venda de ativos.

Para piorar, simultaneamente, o preço médio do barril de petróleo no mercado internacional, depois de três anos de relativa estabilidade, girando próximo dos US\$ 100,00, caiu vertiginosamente entre junho de 2014 e fevereiro de 2016, saindo de US\$108,37 para US\$29,78, respectivamente ${ }^{19}$ (RICETO, 2019). Obviamente, este cenário comprometeu sensivelmente a capacidade de investimentos da estatal brasileira e seu fluxo de caixa, o que, diante de sua carteira de investimentos previstos, forçou a alavancagem.

Porém, antes de adentrarmos na situação da empresa brasileira, é relevante uma breve análise desse "contra-choque" do petróleo. Considerando a (nem sempre) tácita tensão entre os países detentores de grandes reservas e suas estatais frente aos interesses dos países importadores e suas empresas privadas, "[...] muito do que ocorre com o petróleo desde o final da década de 1990 é resultado de decisões que quaisquer que sejam, são tomadas por governos" (YERGIN, 2009, p. 895). Na verdade, Fiori (2018) destaca que hoje, das 20 maiores petroleiras do mundo, 15 são estatais e controlam cerca de $80 \%$ das reservas conhecidas mundialmente, logo as principais decisões relativas ao petróleo (produção, regulamentação e preços) passam efetivamente pelos interesses dos Estados e de suas empresas públicas, ou seja, são os interesses e as alianças políticas que, no final do dia, determinam o preço internacional do petróleo. Afinal, tais acordos precedem as compras desse recurso tão estratégico e necessário, já que, as relações comerciais com inimigos são evitadas nestes arranjos (ARAÚJO, 2018).

Ainda que pese a complexidade do mercado de petróleo e dos fatores que interferem na composição de seu preço, o referido cenário, de acentuada queda de sua cotação entre 2014 e 2016, pode ser compreendido pela somatória de dois grandes movimentos: o aumento de produção de alguns países, incluindo membros da OPEP, e o desaquecimento da demanda global, em especial pela redução das importações chinesas, decorrente de sua desaceleração econômica, e estadunidenses, que ampliaram a produção doméstica.

De um lado, EUA, Brasil, Rússia, e alguns membros da OPEP, como Arábia Saudita, Iraque e Irã incrementaram consideravelmente suas produções. Fora da OPEP, os EUA saltaram de pouco mais

18 Disponível em: <https://oglobo.globo.com/economia/setor-naval-fechara-quase-80-mil-vagas-ate-202023031696>. Acessado em 06 mai. 2019.

19 Valor médio mensal para o barril de petróleo bruto, considerando as classificações Brent Dated, West Texas Intermediário e Dubai Fateh, U.E. 
de 302 milhões de toneladas de petróleo, em 2008, para mais de 543 milhões de toneladas, em 2016. O Brasil passou de 94 milhões de toneladas, em 2006, para quase 137 milhões de toneladas, em 2016.

Já dentro da OPEP, o Iraque atingiu um total de 219 milhões de toneladas em 2016, praticamente 60 milhões de toneladas a mais que em 2014. O Irã, depois de assinar o Acordo Nuclear de Viena (2015), voltou a vender petróleo no mercado internacional, já que as sanções que o país sofria foram reduzidas. O Irã ultrapassou a marca de 216 milhões de toneladas em 2016, contra menos de 170 milhões em 2013. A Arábia Saudita, que, segundo a versão oficial, tentava manter sua fatia de mercado, aumentou sua produção em aproximadamente 1,1 milhão bpd, chegando a quase 586 milhões de toneladas, contra pouco menos que 474 milhões de toneladas em 2010 (BECK, 2016; BP, 2017).

Por outro lado, em paralelo com a ampliação da oferta, o aumento da produção doméstica nos EUA, baseada no óleo e gás de xisto, obtido pelo fraturamento hidráulico, técnica cara e ambientalmente questionável, reduziu sensivelmente as importações daquele país. "Entre 2012 e 2015, os Estados Unidos aumentaram sua produção de petróleo de 10 para 14 milhões de barris por dia, ultrapassando a Rússia e a Arábia Saudita" (BECK, 2016).

Concomitantemente a isso, dados do $\mathrm{FMI}^{20}$ mostram que, depois de intenso crescimento econômico na primeira década deste século, com médias próximas a 10\%, a economia chinesa desacelerou consideravelmente. Apesar de ainda apresentar médias percentuais invejáveis a maioria dos países, em 2016, o crescimento do PIB chinês foi de 6,8\%, quase 4 pontos percentuais menor que em 2010, quando cresceu 10,6\%. Este cenário levantou rumores de uma crise ainda mais aguda, em um dos maiores importadores de combustíveis do mundo e contribuiu para o arrefecimento do mercado de petróleo.

Indiscutivelmente, essa rápida queda dos preços afetou países dependentes do mercado de petróleo e gás natural como Rússia, Venezuela e Nigéria, mas também países que apresentam maiores custos de produção, em especial os EUA e o Brasil. Assim, além de muito limitar a movimentação financeira da Petrobras, este quadro ampliou desconfianças sobre a salubridade econômica da empresa e a viabilidade da exploração do pré-sal.

Na realidade, a somatória desses fatores ultrapassaram as condições de um crescimento autossustentado da estatal, tanto em termos financeiros como produtivos de complementação. Esse quadro, somado ao papel estratégico assumido pela estatal em meio às políticas anticíclicas adotadas pelos governos Lula e Dilma diante da crise internacional, resultou em um crescente endividamento da empresa. Nesse sentido,

O que sim existe nesse complicado enlace é um claro nexo entre o endividamento da Petrobras e o papel de liderança atribuído à companhia pelo governofederal na política de investimentos do país. O protagonismo da Petrobras constava do PAC - Programa de Aceleração do Investimento, anunciado em janeiro de 2007. Foi reforçado tanto pela descoberta do pré-sal, (...) quanto pela surpreendente crise financeira mundial em 2008. Frente ao cenário externo adverso, o governo federal procurou acelerar ao máximo o investimento da Petrobras como forma de combater o efeito recessivo da retração mundial. E fez isso de modo a favorecer os fornecedores brasileiros, notadamente as grandes construtoras, definindo metas ambiciosas para o conteúdo local dos equipamentos comprados pela Petrobras, com destaque para as encomendas de construção naval. Mas não basta querer. Metas excessivamente ambiciosas foram além do limite da capacidade tanto da Petrobras quanto dos fornecedores, e desvirtuaram aquela que seria, conceitualmente, uma política virtuosa de estímulo à economia brasileira. (GHIRARDI, 2015, p. 7). 
Os Planos de Negócios e Gestão (PNG) da Petrobras entre 2006 e 2014²1, na Tabela 1, permitem avaliar a evolução dos investimentos e do endividamento da empresa. Os investimentos aumentaram mais de 4 vezes, de US\$ 56,4 bilhões para US\$ 236,7 bilhões (no quadriênio 2013/2017). No PNG 2014/2018, na eminência do súbito declínio de preços e dos desdobramentos da Operação Lava Jato, a previsão era de pouco menos de US\$ 221 bilhões.

Os investimentos no mercado interno dominaram o cenário, variando entre $86 \%$ (2007/2011) e 98,7\% (2013/2017). Tal aumento coincide com a eclosão da crise internacional, com o incremento das medidas anticíclicas e com a viabilização técnica da exploração do pré-sal. Houve ainda um aumento expressivo da taxa prevista para alavancagem, saltando de praticamente zero até o PNG 2007/2011 para um limite máximo de 35\% a partir do PNG de 2012. A partir do PNG 2009/2013, em meio a violenta queda dos preços do petróleo no mercado internacional ${ }^{22}$, a alavancagem financeira ${ }^{23}$ foi significativamente alargada.

Tabela 1 - Planos de Negócios e Gestão (PNG) - 2006/2014

\begin{tabular}{|c|c|c|c|}
\hline PNG & $\begin{array}{c}\text { Investimento Total } \\
\text { (bilhões) }\end{array}$ & $\begin{array}{c}\text { Investimento destinado } \\
\text { ao mercado interno (\%) }\end{array}$ & $\begin{array}{c}\text { \% de alavancagem } \\
\text { frente ao investimento } \\
\text { total }\end{array}$ \\
\hline $2006 / 2010$ & US\$ 56,4 & 87 & - \\
\hline $2007 / 2011$ & US\$ 87,1 & 86 & - \\
\hline $2008 / 2012$ & US\$ 112,4 & 87 & 35 \\
\hline $2009 / 2013$ & US\$ 174,4 & 91 & 35 \\
\hline $2010 / 2014$ & US\$ 224 & 95 & $26-29$ \\
\hline $2011 / 2015$ & US\$ 224,7 & 95 & $25-35$ \\
\hline $2012 / 2016$ & US\$ 236,5 & 97,5 & $25-35$ \\
\hline $2013 / 2017$ & US\$ 236,7 & 98,7 & $>35$ \\
\hline $2014 / 2018$ & US\$ 220,6 & 95,6 & \\
\hline
\end{tabular}

Fonte: <http://www.investidorpetrobras.com.br/pt/apresentacoes/plano-de-negocios-e-gestao>. Organização: RICETO, A. 2019

O PNG 2014/2018, o primeiro a trazer uma redução do investimento no período retratado, reafirmou a política de preços estabelecida pelo Conselho de Administração da empresa em 29 de novembro de 2013, a qual desvinculava os preços domésticos do diesel e da gasolina das variações internacionais e os submetia a reajustes com base na evolução dos indicadores de endividamento e alavancagem da Petrobras. Estabeleceu-se que haveria a convergência de tais preços em um "prazo compatível".

Esse mecanismo, também direcionado ao controle da inflação, fez com que a Petrobras administrasse prejuízos resultantes da importação de petróleo e derivados, uma vez que os reajustes não seriam repassados de imediato ao mercado interno. Com isso, os prejuízos chegaram a mais de US\$ 41 bilhões em 3 anos (2011/2014). De modo mais detalhado

21. Disponível em: <http://www.investidorpetrobras.com.br/pt/apresentacoes/plano-de-negocios-e-gestao>. Acesso em: 20 jul. 2018.

22. Entre julho de 2008 e fevereiro de 2009, o preço médio mensal do barril de petróleo, considerando a média do tipo Brent Dated, West Texas Intermediário e Dubai Fateh, saiu de US\$132,00 para menos de US\$ 42,00 (RICETO, 2019).

23. Alavancagem financeira ocorre quando uma empresa faz uso de capital de terceiros, normalmente a juros fixos, na sua composição de capital e maximiza os resultados para os acionistas. Evidentemente, quanto maior for o grau de alavancagem financeira (GAF) de uma empresa, maiores serão o seu endividamento e, frente a uma gestão equivocada, o seu risco financeiro. 
A queda nos lucros, de US\$20,1 bilhões, em 2010 e 2011, para US\$ 11 bilhões, em 2012 e 2013, era decorrência direta dos prejuízos na revenda de combustíveis (...), como consequência dos controles que o governo federal vinha exercendo nos preços da gasolina e do óleo diesel. Em 2014 (...) os prejuízos com a venda de combustíveis chegaram a US\$ 15,4 bilhões. De 2011 a 2014, o total dos prejuízos (...) US\$ 41 bilhões (...). Em 2015 e 2016, as perdas na comercialização de combustíveis cessaram, em razão da queda nos preços da gasolina e do diesel que a Petrobras importa (...). (MORAIS, 2017, p. 19).

Compondo essa conjuntura, outro agravante dessa situação foi a significativa desvalorização do Real. No fechamento do mês de junho de 2014, o dólar estava cotado a R\$ 2,23. Um ano depois, em junho de 2015, ultrapassou a casa dos R\$ 3,00 e, na última cotação de dezembro de 2015, fechou o ano em R\$3,94, ou seja, desvalorização de mais de $76 \%$. Com cerca de $80 \%$ da sua dívida bruta em moeda estrangeira, principalmente dólares (OLIVEIRA; COUTINHO, 2017), a Petrobras foi severamente prejudicada por esse quadro.

A somatória de todos esses fatores - desvalorização internacional do petróleo, elevação dos investimentos, o controle sobre dos preços de derivados, a perda de valor de mercado pela depreciação de suas ações e pela redução do valor recuperável de seus ativos (impairment), o desvio de recursos e a desvalorização cambial - resultou em prejuízos e no aumento do endividamento da Petrobras.

Morais (2017) mostra que, em 2014, a dívida líquida da empresa foi estimada em mais de US\$ 106 bilhões, praticamente duas vezes a dívida de US\$ 55 bilhões existente em 2011. Cenário ainda pior foi vivido quando, muito em função da acentuada desvalorização do petróleo em 2015, a receita de vendas da empresa foi inferior à dívida líquida em mais de US\$ 3 bilhões, com isso a relação dívida líquida/EBITIDA ${ }^{24}$ alcançou a razão de 5,1, mais que o dobro do índice de 2,5 considerado saudável pelas agências de avaliação de risco. Esse quadro tornou mais custosa a captação de recursos no mercado internacional.

Ainda assim, o endividamento da empresa levanta discussões e divergências de análise. Antes da flexibilização do Marco Regulatório do Pré-sal, ocorrido em novembro de $2016^{25}$, a Petrobras, embora enfrentasse alguns desafios financeiros no curto prazo, apresentava um cenário de médio/longo prazo confortável. Um indicativo disso foram os resultados de três captações de recursos realizadas pela empresa em 2014 e 2015.

Em janeiro de 2014, foram captados mais de 3 bilhões de Euros e 600 milhões de Libras Esterlinas (totalizando naquele momento US\$ 5,2 bilhões), numa operação que foi considerada a maior da história de uma empresa oriunda de um mercado emergente no mercado europeu, contando com mais de 1.300 ordens de compra oriundas da Inglaterra, da Alemanha, da Suíça e da França. Os títulos em Libras foram contraídos com prazo de 20 anos, o que indica credibilidade do mercado.

Em 11 de março de 2014, outra captação alcançou US\$ 8,5 bilhões, sendo destes títulos, US\$ 2,5 bilhões para 10 anos e US\$ 1 bilhão para 30 anos. Nessa ação, a demanda do mercado pelos títulos superou os US\$ 23 bilhões. Já, em maio de 2015, na primeira ação de captação no mercado após as revelações da Operação Lava Jato e de todos os prejuízos causados por essa a imagem da estatal, a empresa arrematou US\$2,5 bilhões de dólares para 100 anos. Nesta, a demanda superou US\$ 13 bilhões ${ }^{26}$.

24. EBITIDA: sigla que, em português, significa "lucro antes de juros, impostos, depreciações e amortizações". É um indicador financeiro para avaliar grandes empresas de capital aberto, pois representa a capacidade de geração de receita a partir de sua atividade (principal) operacional.

25. Estabelecido pela Lei Federal 13.365 de 29 de novembro de 2016.

26. Disponível em: <https://www.valor.com.br/financas/3456662/petrobras-capta-us-85-bilhoes>; <https://br.reuters.com/article/businessNews/idBRKBN0OH2UF20150601>; 
Os prazos e as cifras das demandas retratadas demonstram a confiança do mercado nos investimentos e na gestão da Petrobras, contrariando os discursos e a imagem da empresa produzida pela grande mídia nacional ${ }^{27}$, e corroborava com a perspectiva de Oliveira \& Coutinho (2017) que entendem os projetos no campo da exploração de petróleo e seu retorno financeiro como de longos prazos, e que os investimentos na exploração das reservas do pré-sal, somados à desvalorização cambial entre 2014 e 2015, foram os grandes propulsores do quadro de endividamento, ou seja, fatores conjunturais.

Ao mesmo tempo, deve-se entender que se tratava de um endividamento "lastreado" no protagonismo, econômico e tecnológico, até então exercido pela Petrobras nos consórcios de exploração do pré-sal. Vale ressaltar que o protagonismo garantido pelo Marco Regulatório era condizente com os avanços técnicos de exploração. Avançava-se muito no aumento da produção, na redução do tempo para a perfuração dos poços e dos custos de produção.

Assim, mesmo com as dificuldades momentâneas, ficava "evidente que a capacidade de gerar receita é compatível com o endividamento. Por isso, não faltam recursos quando a Petrobras acessa os mercados de crédito nacional e internacional" (OLIVEIRA; COUTINHO, 2017, p. 5). Apesar dos desafios financeiros de curto prazo [...], a Petrobras possui uma situação positiva, em termos de médio e longo prazo, [...] uma vez que detém novas áreas produtoras competitivas que poderão gerar fluxos de caixa futuros" (PINTO, 2017, p. 2).

Além desse fator, há de se levar em conta que

A robustez da companhia é assegurada pela qualidade do seu corpo técnico, pela produção atual de mais de 2,8 milhões de barris por dia, além de 11 refinarias (mais uma em construção), três terminais de GNL, duas fábricas de fertilizantes e certamente o mais importante ativo estratégico a garantir a sua sustentabilidade a longo prazo, que é sua posição hegemônica num mercado praticamente cativo de um dos mais importantes países do mundo (SOMBRA, 2015, p. 3).

Corroborando com essa perspectiva, Guilherme Estrella ${ }^{28}$ (2018), em entrevista concedida à TV ULBRA, publicada no YouTube, em 22 de janeiro de 2018, argumenta que

\begin{abstract}
(...) a produção do pré-sal é fruto da competência da companhia (...), a Petrobras é a mais competente indústria de petróleo existente no mundo, quanto a isso eu não tenho dúvida, (...) estamos produzindo no pré-sal desde 2010 e a gente não vê uma (ocorrência de acidente), é uma empresa absolutamente segura em suas operações (...). Financeiramente (...) uma empresa que produz dois milhões e meio de barris, que agrega valor também ao produto que vende no mercado nacional e internacional, essa empresa tem um ingresso de mais de US\$ 50 bilhões por ano (...) tem recursos suficientes, reservas petrolíferas suficientes para enfrentar a dívida, que foi contraída lá atrás (...) por que ninguém tinha o pré-sal, (...) o Brasil era o único país que tinha o pré-sal e a Petrobras era a operadora única, então grandes projetos necessitam de grandes investimentos, e foi isso que aconteceu (...).
\end{abstract} <https://pedesenvolvimento.com/2014/01/31/captacao-de-recursos-da-petrobras-na-europa-atinge-e305-bilhoes-e-600-
milhoes/>. Acessos em: 21 jul. 2018.

27. Alguns exemplos: <https://www.infomoney.com.br/petrobras/noticia/2822561/divida-estratosferica-pode-levarpetrobras-falencia-diz-mpf>; $\quad$ <https://exame.abril.com.br/negocios/petrobras-tem-32-de-chances-de-ir-a-falencia-dizmacroaxis/>; <http://g1.globo.com/economia/negocios/noticia/2013/12/petrobras-tem-32-de-chance-de-falir-segundoconsultoria-dos-eua.html>. Acessados em: 20 set. 2019.

28. Geólogo que, concursado, construiu destacada carreira na Petrobras entre as décadas de 1960 e 1990. Depois de aposentado, a convite do ex-presidente Luiz Inácio Lula da Silva, retornou à empresa em 2003 como Diretor de Exploração e Produção (E\&P), cargo que ocupou até 2012. Sob sua gestão, foram descobertas e desbravadas as reservas do pré-sal, o que lhe rendeu o título informal de "pai" dessa nova fronteira de exploração. 
Entre 2010 e 2014, a Petrobras fez investimentos de mais de US\$ 200 bilhões, notadamente na exploração do pré-sal (OLIVEIRA; COUTINHO, 2017). Tais investimentos deram resultados, afinal, desde a perfuração do primeiro poço, em setembro de 2006, a produção vem crescendo, ao passo que os custos de produção e o tempo para perfuração dos poços diminuíram significativamente. Segundo dados do Instituto Brasileiro de Petróleo, Gás Natural e Biocombustíveis (IBP) ${ }^{29}$, o índice médio de sucesso exploratório nas perfurações de poços nas áreas do pré-sal, entre 2012 e 2016, superou os $88 \%$, chegando a $100 \%$ em 2013 .

Dados da pré-sal Petróleo ${ }^{30}$, revelam que, entre maio de 2015 e maio de 2020, a produção de petróleo nestes campos aumentou 158\%, respondendo por aproximadamente $68 \%$ da produção brasileira atual. Esta informação pode ser interpretada de diferentes maneiras: retrata o grande potencial produtivo das reservas, a viabilidade técnica da exploração, mas também o acelerado ritmo de extração destes recursos, que hoje, em grande parte, encontra-se sob os interesses de grandes corporações transnacionais.

Em 29 de novembro de 2016, foi sancionada a Lei Federal no 13.365, a qual derivou do Projeto de Lei no 131/2015, do então Senador José Serra, filiado ao Partido da Social Democracia Brasileira (PSDB), e que alterou artigos do Marco Regulatório do Pré-sal sob o regime de partilha. Entre as alterações mais danosas, em termos estratégicos para a Petrobras e para a segurança energética nacional, a estatal perdeu a exclusividade de operar os consórcios de exploração dessa nova fronteira.

Com a nova legislação, para que a Petrobras seja a operadora dos consórcios contratados para a exploração de novos blocos no pré-sal, é necessário que, em até 30 dias, após autorização do Conselho Nacional de Política Energética (CNPE) para o leilão e sua devida publicação no Diário Oficial da União (DOU), a empresa manifeste interesse em operar a exploração. Com isso, e considerando a drástica redução dos investimentos e a venda de ativos pela empresa sob o argumento de liquidar dívidas, abre-se a possibilidade de outras empresas, em especial as grandes transnacionais, operarem blocos nessa nova fronteira.

Partindo do fato de que a Petrobras é uma empresa estatal, cujo maior acionista é a União Federa $^{31}$, deve cumprir um papel estratégico para o país e se ela fosse a única operadora, traria vantagens, tais como: 1) maior controle sobre a taxa de exploração das reservas, evitando a extração predatória ou mesmo a subestimação do volume explorado; 2) maior clareza sobre os custos dos empreendimentos de produção; 3) a promoção de uma política industrial capaz de estimular o desenvolvimento de outros setores da economia brasileira - com base na Política de Conteúdo Local (PCL) - consequentemente a geração de tecnologias e empregos dentro do país; 4) maior acesso da União, direta ou indiretamente, à parcela do óleo lucro advindo do modelo de partilha; 5) a relativa compatibilidade entre a produção e a demanda interna, em alguns momentos, a autossuficiência em volume bruto, como já alcançada conjunturalmente em algumas oportunidades; 6) além do retorno dos volumosos investimentos realizados pela empresa no mapeamento e na análise das reservas dessa nova fronteira (AEPET, 2015).

O que vem ocorrendo nos últimos anos, em especial desde as alterações no Marco Regulatório de 2010, é uma guinada na perspectiva da empresa como a redução radica de investimentos, a venda

29. Disponíveis em: <https://www.ibp.org.br/observatorio-do-setor/sucesso-exploratorio/>. Acesso em: 28 jul. 2018.

30. Empresa pública, organizada na forma de sociedade anônima de capital fechado, vinculada ao Ministério de Minas e Energia (MME). Disponível em: <http://www.presalpetroleo.gov.br/ppsa/o-pre-sal-em-numeros/evolucao-da-producao-depetroleo-pre-sal-x-pos-sal>. Acessado em: 27 jul. 2020.

31. Em 30 de junho de 2018, 50,26\% das ações ordinárias (ON) da empresa pertenciam à União Federal. Somando esse percentual aos pertencentes ao BNDES e à Caixa Econômica Federal, outros dois bancos públicos, chegava-se a mais de 63,5\%. Ao mesmo tempo, 46,2\% do capital social da empresa pertenciam a essas mesmas entidades. Disponível em: <http://www.investidorpetrobras.com.br/pt/governanca-corporativa/capital-social>. Acesso em: 30 jul. 2018. 
de ativos, deixando de ser uma companhia integrada, bem estruturada no sistema "do poço ao posto", para uma empresa dependente da importação de derivados, tecnologias e que está concentrando sua atuação no setor de exploração e produção, além de abdicar de setores estratégicos e lucrativos como o refino e comércio de derivados.

Dentre os ativos vendidos nesse período, destacam-se: aproximados $2.500 \mathrm{~km}$ de gasodutos na região Sudeste; a participação da empresa (66\%) no consórcio de exploração do bloco BM-S-8, no campo de Carcará, na Bacia de Santos (REUTERS, 2016). Já em 2017, foram vendidos 1/4 da participação da empresa no Campo de Roncador, na Bacia de Campos, e do campo do Azulão, na Bacia do Amazonas. Além disso, em dezembro de 2017, foi realizada a abertura de capital da BR Distribuidora, com a venda de quase 335.000.000 ações, representando cerca de 30\% da companhia (NUNES; LUNA, 2017). Em 2018, o campo da Lapa e a área de lara, ambas no pré-sal da Bacia de Santos, foram vendidas à Total (francesa).

Em 30 de janeiro de 2019, a empresa anunciou a venda da refinaria de Pasadena, no Texas (EUA) para a estadunidense Chevron por US\$ 562 milhões, cerca de 1/3 do valor final investido para sua aquisição, US\$ 1,885 bilhão ${ }^{32}$. Em novembro, a estatal assinou o contrato de venda de todas as suas ações da subsidiária Liquigás, que atua no engarrafamento, na distribuição e na venda de gás liquefeito de petróleo (PLATONOW, 2019).

Seguindo esta nova lógica pregada pela direção da empresa e pelo governo federal, de priorizar investimentos de retorno rápido, foi vendida a participação da Petrobras no consórcio de exploração do campo de Carcará. Sem total clareza da extensão vertical de suas reservas, essa província, que vinha sendo prospectada pelo consórcio operado pela Petrobras desde 2012, é considerada uma das mais promissoras já mapeadas no pré-sal. As reservas recuperáveis chegam a mais de 2,6 bilhões de barris de óleo estimado (boe), simplesmente o dobro do estipulado no ato da compra do ativo pela Equinor, 1,3 boe (AEPET, 2018).

Além disso, sistemas logísticos de distribuição de gás natural também foram vendidos. 0 sistema de distribuição de gás natural da região Sudeste, adquirido pelo consórcio liderado pela empresa canadense Brookfield Asset Management, por US\$ 5,2 bilhões, correspondeu inicialmente a 90\% das ações da malha da Nova Transportadora do Sudeste (NTS), agora NTS S/A. Tal estrutura de distribuição compunha um sistema logístico integrado de abastecimento derivado de uma série de aquisições feitas pela Petrobras ao longo dos últimos quinze anos ${ }^{33}$. A NTS detém um sistema integrado ao gasoduto Brasil-Bolívia (GASBOL) e responde pelo abastecimento de $50 \%$ do mercado nacional, envolvendo os estados de Minas Gerais, Rio de Janeiro e São Paulo.

Destaca-se a disposição da atual gestão do país e da estatal de seguir com tais vendas, mesmo que isso desarticule o sistema produtivo brasileiro, correndo o risco de reduzir sua eficiência e de

32. Disponível em: < https://www.infomoney.com.br/petrobras/noticia/7903343/aporte-de-us-19-bi-venda-por-us-562-mi-ahistoria-de-pasadena-que-a-petrobras-quer-esquecer>. Acesso em: 17 fev. 2019.

33. Em 2003, frente ao aumento do consumo de gás natural no Brasil e para atender ao Projeto Prioritário de Termeletricidade (PPT), foi lançado o Projeto Malhas, o qual ampliou as malhas de gasodutos do Nordeste e do Sudeste do país. Inicialmente, essa associação visava atender dois acordos para transporte de gás por meio da construção e da operação de gasodutos nas regiões citadas. O consórcio era liderado pela Transportadora Associada de Gás (TAG), da Petrobras, e era composto por Nova Transportadora Nordeste (NTN), Nova Transportadora Sudeste (NTS), Transportadora Nordeste e Sudeste (TNS), e Petrobras Transporte (Transpetro). Os primeiros gasodutos, nas regiões nordeste e sudeste, foram entregues em 2006. Em 2008, em momento de força da Petrobras e euforia com a descoberta do pré-sal, a TAG deu início à sua consolidação por meio da compra de outros ativos no setor de transporte de gás natural. Naquele ano, a transportadora da Petrobras adquiriu a TNS e a Transportadora Capixaba de Gás (TCG), já em 2010, a compra foi da Transportadora Urucu Manaus (TUM), em 2012, da Transportadora Gasene e, finalmente, em 2014, da própria NTS e da NTN. Com isso, a Petrobras, por meio da TAG, passava a ter protagonismo inédito no setor, concentrando operações nos maiores mercados de consumo de gás natural do país. Disponível em: < https://www.ntsbrasil.com/>. Acesso em: 06 ago. 2018. 
aumentar os custos internos de produção de derivados. Ao mesmo tempo, como já demonstrado, as justificativas usadas - de endividamento e restrições de capacidade de investimentos - não se sustentam diante das próprias características da cadeia do petróleo, do escalonamento da dívida, do lastro até então fornecido pelo pré-sal, pelo know-how da empresa e das características estratégicas dos ativos. Assim, o que se acompanha é um desmonte da estrutura produtiva e do gigantismo estratégico até então alcançados pela Petrobras ao longo de sua história, principalmente neste século.

\section{Considerações finais}

A história da Petrobras sempre foi permeada por aspectos estratégicos de grande relevância para o Brasil. No início deste século não foi diferente. Sob os governos Lula e Dilma, a estatal se transformou num propulsor do desenvolvimento socioeconômico do país, em especial após a descoberta das reservas da camada pré-sal em 2006 e da crise internacional de 2007/08. Nesse cenário, o circuito espacial produtivo do petróleo passou a ser a base de uma estratégia geoeconômica do Estado brasileiro.

Estabelecendo um novo marco regulatório, essa nova fronteira exploratória passou a ser entendida como uma oportunidade de desenvolvimento tecnológico e econômico do país. Essa nova regulamentação para concessão das áreas do pré-sal estabeleceu o regime de partilha que fazia da Petrobras a única operadora dos consórcios, concedeu áreas com elevado potencial exploratório a estatal, aprofundou significativamente a Política de Conteúdo Local (PCL) e ainda criou o Fundo Social do Pré-Sal (FSPS).

Dessa forma, o Estado brasileiro, representado por seus órgãos, como o Conselho Nacional de Política Energética (CNPE), e pela Petrobras, em parceria com o capital privado nacional e internacional, poderia direcionar o melhor aproveitamento da exploração dessa nova fronteira, ditando um ritmo exploratório voltado aos interesses do mercado (doméstico e estrangeiro) mas também aos do Estado. Poderia formar estoques estratégicos para garantir a estabilidade do mercado interno, um dos maiores do mundo, e ainda fomentar programas de desenvolvimento social e tecnológico com o FSPS.

Além disso, tais elementos somados a PCL, cujos percentuais são estipulados nas licitações, serviu para impulsionar vários setores complementares, de uma forma como há muito não se via no país. Dentre estes, no curto período em que o novo regramento dado pela versão original do Marco Regulatório (Lei Federal 12.351/10) se estabeleceu, o setor de engenharia e da construção naval se despontaram.

A partir da descoberta das reservas do pré-sal, a Petrobras concentrou seus investimentos no mercado brasileiro para viabilizar tal exploração. Diante de grandes desafios financeiros e tecnológicos, elevou sensivelmente seus investimentos entre 2006 e 2014 e firmou parcerias com mais de uma centena de universidades do país, fomentando neste período a esmagadora maioria dos investimentos em PD\&l no setor de petróleo e gás natural.

O direcionamento dado pelo Estado à forma de exploração do pré-sal, indubitavelmente, foi um dos pilares da fase socioeconômica próspera vivida pelo país, mesmo diante da crise internacional. As demandas promovidas por tais investimentos impulsionaram a criação de empregos e renda em setores complementares, como a indústria naval que viu o número de trabalhadores aumentar onze vezes entre 2003 e 2014, e teve grande relevância no crescimento do PIB brasileiro. Além do quê, alargaram as fronteiras tecnológicas em diferentes setores e estimularam a qualificação da mão de obra. 
Entretanto, a partir de 2014, tal quadro começa a se inverter. Os estragos causados pela forma como foi conduzida a Operação Lava Jato que, ganhando contornos de espetáculo midiático, difamou a estatal e foi usada como ferramenta política para o redirecionamento da composição do governo brasileiro, o "contrachoque" do petróleo (2014-2016), a acentuada desvalorização do Real e dos ativos da empresa, a política de controle dos preços de derivados e os planos de investimentos da Petrobras, levou a empresa a um crescente endividamento.

Tal quadro, de fato, exigia uma reavaliação dos planos de gestão da empresa. Porém, desde então, o que se estabeleceu foi uma política de desmonte do sistema integrado de produção (modelo "do poço ao posto"). A empresa, em especial a partir de 2016, já sob a presidência de Pedro Parente, no governo de Michel Temer (MDB), viu seu protagonismo, nessa nova fronteira exploratória, ser dilapidado a partir das mudanças no Marco Regulatório, perdendo a posição de única operadora e com isso parte de seu lastro junto ao mercado internacional. Nesse cenário, o ritmo de exploração do pré-sal foi acelerado e a entrada do capital estrangeiro nos consórcios ampliada.

Considerando a estrutura e o papel desempenhado pela Petrobras ao longo de sua história, a posição dessa empresa no que se refere ao abastecimento energético nacional e, principalmente, no desbravamento do pré-sal, é muito mais interessante para o país que ela esteja à frente da operação dos consórcios e mantenha seu sofisticado padrão tecnológico. Afinal, apoiada em um planejamento estratégico de caráter geoeconômico, a estatal poderia voltar às suas atividades de E\&P para o desenvolvimento de outros setores da economia brasileira, como vinha ocorrendo com a Política de Conteúdo Local (PCL).

Usando como justificativa as dificuldades financeiras da estatal a curto prazo, a nova gestão deu início a um amplo processo de liquidação de ativos e desinvestimentos. Muitos dos ativos estratégicos, como a participação na exploração de campos com grande capacidade produtiva no pré-sal, como o de Carcará, a propriedade de sistemas de distribuição de gás natural, e de refinarias, como a de Pasadena (EUA), a qual facilitaria o acesso da Petrobras ao mercado estadunidense, foram liquidados. A venda de ativos segue, sendo as refinarias brasileiras, em grande parte recentemente reestruturadas, um dos próximos alvos.

Com base no exposto ao longo deste trabalho, não há dúvidas: a forma como foi conduzida a Operação Lava Jato, à margem da lei pela conduta de promotores e juízes e ao estabelecer relações nada republicanas com organismos de outros países, notadamente dos EUA, como $\mathrm{FBI}^{34}$, e os contornos políticos que deram a ela transformando-a em um instrumento político de promoção de algumas figuras públicas e execração de outras, trouxeram graves prejuízos socioeconômicos ao país. Incalculáveis. As informações desta operação, obtidas e reveladas por grandes veículos de mídia, construiu uma verdadeira guerra publicitária, responsável, em grande medida, pela desvalorização de ativos e ações das empresas nacionais, elevando assim seus endividamentos.

Dilacerou não só a imagem da principal empresa nacional, mas também de outras empresas privadas de setores complementares, como as grandes empreiteiras (Odebrecht, Camargo Correia, Andrade Gutierrez, entre outras) e estaleiros, que também se viram obrigados a encerrar projetos de desenvolvimento tecnológico, demitir funcionários e vender ativos. Com isso, desarticulou a cadeia de produção que vinha sendo alimentada pela somatória de investimentos, arruinando setores que, há muito, não viviam fase tão virtuosa. Abriu espaço para uma profunda crise política que levou o país a um processo de impeachment considerado por muitos analistas profundamente contestável, e a

34. Como recentemente revelados pelo The Intercept Brasil (2019) e pela Agência Pública (2020). Disponíveis em: < https://theintercept.com/series/mensagens-lava-jato/>e <https://apublica.org/2020/07/o-fbi-e-a-lava-jato/>. Acessado em 31 jul. de 2020. 
uma grave instabilidade institucional. Assim, perdeu-se investimentos, o que colaborou para a precarização ainda maior das condições de vida da população.

Assim, sob o discurso demagógico de combate à corrupção, está em curso o desmonte de avanços alcançados em anos e às custas de bilhões de dólares investidos. O combate à corrupção deve fazer parte do cotidiano de qualquer sociedade que se proponha mais justa e digna, mas isso não deve ser usado como pretexto para o desmonte do patrimônio produtivo nacional. Não se deve comprometer os avanços tecnológicos, econômicos e sociais alcançados na luta pela soberania nacional e o desenvolvimento. Trata-se ainda de uma questão geopolítica e de posicionamento dentro da Divisão Internacional do Trabalho (DIT). A defesa da soberania e o posicionamento assumido dentro do atual Sistema Internacional, manter-se como periférico ou buscar maior influência e protagonismo passam necessariamente pelo arcabouço tecnológico e econômico de um país, algo que certamente não será promovido espontaneamente pelas transnacionais. 


\section{Referências}

ARAÚJO, André. O preço do petróleo é sempre político. Disponível em: <https://jornalggn.com.br/forapauta/o-preco-do-petroleo-e-sempre-politico-por-andre-araujo>. Acesso em: 12 jul. 2018.

ASSOCIAÇÃO DOS ENGENHEIROS DA PETROBRAS. As 14 principais razões porque a Petrobrás deve ser a operadora única do Pré-sal. AEPET Notícias, Rio de Janeiro, Ed. 411, jun. 2015, p. 5-8. Disponível em:

<http://www.aepet.org.br/uploads/paginas/uploads/File/Aepet_Noticias_PDFs/AEPET_NOTICIAS_4 11_EDICAO_ESPECIAL2_versao_net.pdf>. Acesso em: 25 jul. 2018.

Globo falseia números sobre venda de Carcará. AEPET. Disponível em: < https://www.aepet.org.br/w3/index.php/conteudo-geral/item/2064-globo-falseia-numeros-sobrevenda-de-carcara>. Acesso em: 23 jul. 2018.

AZEVEDO, Paola. A desarticulação do parque tecnológico de petróleo. Rio de Janeiro, 16 jan. 2018. Disponível em: <http://www.ineep.org.br/index.php/publicacoes/artigos/item/130-a-desarticulacaodo-parque-tecnologico-de-petroleo>. Acesso em: 17 jul.2018.

BECK, Johannes. Oito motivos para a queda do preço do petróleo. Deutsche Welle - DW, Boon, 16 fev. 2016. Disponível em: <https://www.dw.com/pt-br/oito-motivos-para-a-queda-do-pre\%C3\%A7o-dopetr\%C3\%B3leo/a-19051686>. Acesso em: 16 jul. 2018.

BRASIL. Lei 12.351, de 22 de dezembro de 2010. Dispõe sobre a exploração e a produção de petróleo, de gás natural e de outros hidrocarbonetos fluidos, sob o regime de partilha de produção, em áreas do pré-sal e em áreas estratégicas e dá outras providências. Disponível em: <http://www.planalto.gov.br/ccivil_03/_ato2007-2010/2010/lei/L12351.htm>. Acesso em: 08 jun. 2017.

Lei 13.365, de 29 de novembro de 2016. Altera a Lei n 12.351, de 22 de dezembro de 2010, para facultar à Petrobras o direito de preferência para atuar como operador e possuir participação mínima de 30\% (trinta por cento) nos consórcios formados para exploração de blocos licitados no regime de partilha de produção. Disponível em: <http://www.planalto.gov.br/ccivil_03/_Ato20152018/2016/Lei/L13365.htm>. Acesso em: 08 jun. 2017.

Ministério da Fazenda - Secretaria de Política Econômica. Impactos da redução dos investimentos do setor de óleo e gás no PIB. Disponível em: <https://fup.org.br/gt-pauta-pelobrasil/item/18869-impacto-da-reducao-dos-investimentos-do-setor-de-oleo-e-gas-no-pib-mme-emf>. Acesso em: 17 agos. 2020.

BRITISH PETROLEUM. Statistical Review of World Energy 2017. Disponível em: <https://www.connaissancedesenergies.org/sites/default/files/pdf-actualites/bp-statistical-reviewof-world-energy-2017-full-report.pdf>. Acesso em: 08 fev. 2018.

Consórcio liderado por Brookfield paga US\$5,2 bi por 90\% da NTS, da Petrobras. REUTERS, São Paulo, 23 set. 2016. Disponível em: <https://br.reuters.com/article/topNews/idBRKCN11T1C3>. Acesso em: 12 mai. 2018.

EGLER, Cláudio Antônio Gonçalves; MATTOS, Margarida Maria C. L. (2012) Multinacionais do setor petrolífero, geoeconomia e integração regional da América do Sul. In: MONIÉ, F.; BINSZTOK, J. (Org.) Geografia e Geopolítica do Petróleo. Rio de Janeiro: Mauad X, p. 81-104.

ESTRELLA, Guilherme. TV ULBRA, publicado em 22/01/2018. Disponível em: <https://www.youtube.com/watch?v=EUYAHjt3qRw>. Acesso em: 30 jul. 2018.

FEDERAÇÃO ÚNICA DOS PETROLEIROS - FUP. PETROBRAS, Relatório final Pauta pelo Brasil. Disponível em: <http://fup.org.br/pdf/gt.pdf>. Acesso em: 30 jun. 2018. 
FIORI, José Luís da Costa. Petróleo: uma decisão urgente. (2019) In: LEÃO, R.; NOZAKI, W. (Org.) Geopolítica, estratégia e petróleo: transformações internacionais e nacionais. Rio de Janeiro: INEEP; FLACSO, p. 31 - 33.

A Ordem Mundial do Petróleo. Instituto de Estudos Estratégicos de Petróleo, Gás Natural e Biocombustíveis (INEEP), Rio de Janeiro, 09 jul. 2018. Disponível em: <http://www.ineep.org.br/index.php/publicacoes/colunistas/item/285-a-ordem-mundial-dopetroleo>. Acesso em: 17 jul. 2018.

GHIRARDI, André Garcez. Petrobras: as causas da crise, além da Lava Jato. Carta Capital, São Paulo, 11 agos. de 2015. Disponível em: <https://www.cartacapital.com.br/blogs/outraspalavras/petrobras-as-causas-da-crise-alem-da-lava-jato-305.html>. Acesso em: 15 jul. 2018.

GOULART, Josette. Petrobrás perde R\$ 610 bi na Bolsa e vale menos do que antes do pré-sal. O Estado de São Paulo, São Paulo, 14 dez. 2014. Disponível em: <https://economia.estadao.com.br/noticias/geral,petrobras-perde-r-610-bi-na-bolsa-e-vale-menosdo-que-antes-do-pre-sal,1606666>. Acesso em: 15 jul. 2018.

INSTITUTO DE PESQUISA ECONÔMICA APLICADA. Ressurgimento da indústria naval no Brasil: (20002013). Brasília: Ipea, $2014 . \quad$ Disponível em: <https://www.ipea.gov.br/portal/index.php?option=com_content\&view=article\&id=23082>. Acesso: 24 jul. 2020.

LOURAL, Marcelo S. (2016) Investimentos industriais no Brasil: uma análise setorial do período 19992013. Tese (Doutorado em Ciências Econômicas) - Instituto de Economia da Universidade Estadual de Campinas, Campinas.

MORAIS, José Mauro de. PETROBRAS: crise financeira e de credibilidade e recuperação recente. Disponível em: <http://repositorio.ipea.gov.br/bitstream/11058/8111/1/Radar_n53_Petrobras.pdf>. Acesso em: 10 jun. 2018.

NOZAKI, William. Os impactos econômicos da Operação Lava Jato e o desmonte da Petrobras. Disponivel em: < https://jornalggn.com.br/crise/ineep-os-impactos-economicos-da-operacao-lavajato-e-o-desmonte-da-petrobras/>. Acesso em: 22 out. 2018.

NUNES, Fernanda; LUNA, Denise. Venda de ativos rende US\$ 17 bi à Petrobras. O Estado de São Paulo, São Paulo, 18 dez. 2017.2 Disponível em: <http://economia.estadao.com.br/noticias/negocios,petrobras-vende-25-da-participacap-no-campodo-roncador-para-statoil,70002123869>. Acesso em: 15 mai. 2018.

OLIVEIRA, Cláudio; COUTINHO, Felipe. O Mito da "Petrobras quebrada". Disponível em: <http://www.aepet.org.br/uploads/paginas/uploads/File/ClaudioFelipe.pdf>. Acesso em: 10 jun. 2018.

PINTO, Eduardo Costa. Endividamento da Petrobrás: mitos e verdades.

Disponível em: https://www.fup.org.br/geep-fup/item/21291-endividamento-da-petrobras-mitos-everdades. Acesso em 08 agos. 2018.

PINTO, Eduardo Costa; DWECK, Esther. Redução dos investimentos da Petrobras: um balanço das perdas. Disponível em: <https://www.ineep.org.br/post/redu\%C3\%A7\%C3\%A3o-dos-investimentosda-petrobras-um-balan\%C3\%A7o-das-perdas>. Acesso em: 05 jul. 2019.

PINTO, Eduardo Costa; PEREIRA, Cloviomar Cararine. Desinvestimento da Petrobras: impactos sobre o PIB e o Emprego. Disponível em: <http://www.ie.ufrj.br/intranet/ie/userintranet/ ienamidia/arquivo/211220171348_Jornal_GGN.pdf>. Acesso em: 10 jun. 2018.

PLATONOW, Vladimir. Petrobras assina contrato de venda da Liquigás por R\$ 3,7 bilhões. Agência Brasil, Rio de Janeiro, 19 nov. 2019. Disponível em: 
https://agenciabrasil.ebc.com.br/economia/noticia/2019-11/petrobras-assina-contrato-de-vendada-liquigas-por-r-37-bi. Acesso: 30 jul. 2020.

RICETO, Álisson. INTEGRAÇÃO ENERGÉTICA DA AMÉRICA DO SUL: o papel da Petrobras na articulação dos territórios a partir da cadeia do petróleo e do gás natural. Dissertação (Mestrado em Geografia) - Instituto de Geografia da Universidade Federal de Goiás - Regional Catalão (UFG/RC), Catalão, 2019 Disponível em: <https://repositorio.bc.ufg.br/tede/bitstream/tede/9654/5/Disserta\%c3\%a7\%c3\%a30\%20\%20\%c3\%81lisson\%20Riceto\%20-\%202019.pdf>. Acessado em: 18/06/2019.

SOMBRA, José Luiz. O que a imprensa não conta. AEPET Notícias, Rio de Janeiro, Ed. 411, jun. 2015, p. 2-3. Disponível em: <http://www.aepet.org.br/uploads/paginas/uploads/File/Aepet_Noticias_PDFs/AEPET_NOTICIAS_4 11_EDICAO_ESPECIAL2_versao_net.pdf>. Acesso em: 25 jul. 2018.

YERGIN, Daniel. (2009) O Petróleo: uma história mundial de conquistas, poder e dinheiro. Rio de Janeiro: Paz e Terra. 